\title{
Spring recoil and supraglottic airway devices: lessons from the law of conservation of energy
}

In the Oxford dictionary, recoil is rebound or spring back through force of impact or elasticity [1], and this term is widely used with particular reference to automatic weapons. In this specific setting, the recoil spring is used to compensate and absorb the bullet force momentum and to convert energy into the activation of a weapon's reloading system. Based on the principle of energy conservation, this is an example of how we could use for a different (and useful) purpose a simple physical phenomenon.

In this issue of the Romanian Journal of Anaesthesia and Intensive Care, Corda and co-workers [2] present an interesting paper based on the same conceptual principle: using the physical recoil of a laryngeal mask pilot balloon valve to adjust the mask's intracuff pressure and keep it within safety levels.

This approach was already described in vitro [3], while in their paper Corda and co-workers elegantly demonstrate the efficacy and safety of this technique also in vivo, underlining its reproducibility and absence of extra costs, hence promoting its routine use to increase supraglottic airway devices' (SADs) safety and benefits for the patients.

Since their introduction to anaesthetic practice [4] and through their evolution [5], SADs have become first the main rescue airway as in all international guidelines [6], and with time also a part of our standard clinical practice. There are a large number of devices available, with specific and different features and with quite precise indications, applications and limitations [7].

Recent data from NAP4 [8] confirm how extensive the SADs use is and that some major issues, mostly represented by limited airway protection and risk of aspiration, need to be reconsidered, the tracheal tube being not so safe. Their applications and indications are increasing [9] and more and more clinicians trust this safe alternative to conventional endotracheal intubation, also on account of less side effects, risks and

Address for correspondence:

Massimiliano Sorbello AOU Policlinico Vittorio Emanuele Via Genova, 80 - 95127

Catania, Italy

E-mail: maxsorbello@gmail.com complications [10]. It may be simpler to use but simple does not always mean easy.

The increased use of SADs unavoidably has led to a greater awareness and collection of data on their safety and on patient outcomes, giving back some surprising data regarding "minor" issues such as postoperative sore throat, dysphagia and oropharyngeal postoperative symptoms. Different figures are available, and keeping account of different definitions, timing, used SADs and techniques, we could estimate an average $20-40 \%$ incidence of these symptoms $[2,11-$ 13], which strongly argues against the supposed benefit of SADs' use.

There is an active body of research for predicting difficult SAD insertion and performance [14], whereas clear data and scientific evidence for SADs position check and for cuff pressure management are somehow missing, despite a long standing awareness that most of the SADs' related side effects and complications depend upon the malposition or an uncontrolled intracuff pressure [15]. Recent data suggest that probably many of our used SADs, despite clinical effectiveness, are probably misplaced or incorrectly placed [16].

Certainly, we are entering a new world, and a new cultural approach to $S A D$-anaesthesia, which is not (and probably cannot be) a simple shift of our habits and techniques from the endotracheal tube to a simpler anaesthetic technique. Particularly, avoiding the misleading concept that, SAD being simpler (but not easier) we can downscale our attention and simply make everything easier. We probably rarely see tracheal stenosis as a consequence of an overinflated endotracheal tube cuff, because it does not occur so often and in all patients with a supra-distended cuff; or, maybe better, it is not diagnosed so often [17]. Many patients go missing in follow-ups and many stenosis are clinically insignificant and then probably undiagnosed [18].

On the other hand, an overinflated SAD's cuff, or a partly misplaced SAD, may not have any clinical meaning during our general anaesthesia, thus passing unobserved. Occurrence of dysphagia or sore throat might as well be accepted by the patient as a minor (and unavoidable) issue, not much more than pain at a venipuncture. And on the other hand, these symptoms might be largely underestimated by anaesthetists, simply 
because apart from research studies, probably, the majority of them do not enquire about these patients' manifestations.

If we use SADs to improve the quality of our anaesthetic practice, in the idea of a faster surgical turnover [19], reduced drug consumption and administration [20], lower dental potential damage $[21,22]$, better postoperative pulmonary function [23], lower hemodynamic impact [24], we then need to adapt our practice to this new anaesthetic approach and start to consider SADs intracuff pressure monitoring as mandatory.

This issue is also perceived by the market and by industries, whose response have been self-pressurizing devices [25], capable of adapting intracuff pressure to surrounding tissues, or thermopolimeric cuff devices [26], which change their shape and consequential developed pressures based on thermo-adaptability. Other solutions have been proposed, including SADs with an embedded cuff monitoring system, sustained by evidence that continuous cuff monitoring reduces oropharyngeal side effects [27], with similar reliability to an electronic manometer and largely better performance than (subjective) digital palpation [28] originally suggested by Dr. Brain. This also evidences the raw reality that, when subjectively or empirically monitored, cuff pressure can easily reach values 3-5 times greater than the recommended safety thresholds [10].

Adding this monitoring to our daily practice might also result in further benefits, as suggested by some authors, claiming that a cuff pressure check could also address malposition diagnosis [29]. The use of continuous SAD cuff pressure monitoring, relying on Boyle's law and relative pressure variations due to oropharyngeal and cricopharyngeal muscles tone, could also add potentially valuable information on anaesthetic plan adequacy and on our pharmacological choices. Not forgetting that intracuff pressure is not a static value, as it changes because of temperature, exposure to anaesthetic gases such as nitrous oxide, patient position and muscular activity, so that oropharyngeal symptoms might arise also with an initially correctly inflated cuff, but later overinflated or somehow squeezed by an incorrectly anaesthetized patient [30].

The research from Corda [2] gives us a simple, cheap and reliable tool to remember and to control important, though underestimated, clinical information. And generally, it suggests to us to use any available tool (manometry, syringe recoil, cuff-pressure embedded monitors) to control, adjust and optimize SADs' cuff pressure offering simple and easily available data with significant implications on patients' well-being and qualitative outcome.

Further studies are required, and similar research is somehow also a call for a better comprehension of $S A D$-anaesthesia needs, with special emphasis for sizing rules, indications, learning curves, adequacy of anaesthesia and continuous cuff pressure monitoring [31]. All points which could, through different mechanisms, influence the presence (and severity) of oropharyngeal symptoms if not more severe complications.

The newer and high-performance SADs are really powerful weapons in the anaesthetics trolleys and armories. As for high-performance guns, they have a recoil; as we did for weapons, we need to understand and to use them for our purpose and advantage, namely the patients' safety and well-being.

Massimiliano Sorbello

Anaesthesia and Intensive Care, AOU Policlinico Vittorio Emanuele, Catania, Italy

Ivana Zdravkovic

Department of Anaesthesia and Reanimation, Clinical Hospital Center "Zvezdara"

Belgrade, Serbia

Rita Cataldo

Unit of Anesthesia, Intensive Care and Pain Management, Department of Medicine, Campus Bio-Medico University, Rome, Italy

Ida Di Giacinto

Anaesthesia, Polyvalent Intensive Care and Transplantation Unit, Department of Organ Failure and Transplantation, S. Orsola-Malpighi Hospital, Bologna, Italy

\section{Conflict of interest}

Nothing to declare

\section{References}

1. https://en.oxforddictionaires.com/definition/recoil (accessed april 2018)

2. Corda DM, Robards CR, Rice MJ, Morey TE, Gravenstein N, Vasilopoulos T, Brull SJ. Clinical application of limiting laryngeal mask airway cuff pressures utilizing inflating syringe intrinsic recoil. Rom J Anaesth Intensive Care 2018; 25: 11-18

3. Rice MJ, Gravenstein NL, Brull SJ, Morey TE, Gravenstein N. Using the inflating syringe as a safety valve to limit laryngeal mask pressure. J Clin Monit Comput 2011; 25: 405-410. doi: 10.1007/s10877-011-9319-8

4. Agrò FE, Cataldo R, Mattei A. New devices and techniques for airway management. Minerva Anestesiol 2009; 75: 141-149

5. Sorbello M. Evolution of supraglottic airway devices: the Darwinian perspective. Minerva Anestesiol 2018; 84: 297-300. doi: $10.23736 / \mathrm{S} 0375-9393.18 .12680-0$ 
6. Frova G, Sorbello M. Algorithms for difficult airway management: a review. Minerva Anestesiol 2009; 75: 201-209

7. Sorbello M, Petrini F. Supraglottic airway devices: the search for the best insertion technique or the time to change our point of view? Turk J Anaesthesiol Reanim 2017; 45: 76-82. doi: 10.5152/TJAR.2017.67764

8. Cook TM, Woodall N, Frerk C; Fourth National Audit Project. Major complications of airway management in the UK: results of the Fourth National Audit Project of the Royal College of Anaesthetists and the Difficult Airway Society. Part 1: anaesthesia. Br J Anaesth 2011; 106: 617-631. doi: 10.1093/bja/ aer058

9. Petrini F, Di Giacinto I, Cataldo R, Esposito C, Pavoni V, Donato $\mathrm{P}$, et al. Perioperative and periprocedural airway management and respiratory safety for the obese patient: 2016 SIAARTI Consensus. Minerva Anestesiol 2016; 82: 1314-1335

10. Yu SH, Beirne OR. Laryngeal mask airways have a lower risk of airway complications compared with endotracheal intubation: a systematic review. J oral Maxillofac Surg 2010; 68: 23592376. doi: 10.1016/j.joms.2010.04.017

11. L'Hermite J, Dubout E, Bouvet S, Bracoud LH, Cuvillon P, Coussaye JE, et al. Sore throat following three adult supraglottic airway devices: A randomised controlled trial. Eur J Anaesthesiol 2017; 34: 417-424. doi: 10.1097/EJA.0000000000000539

12. Zanella A, Vega E, Ingelmo PM. What am I compressing with my supraglottic device? Minerva anestesiol 2017; 83: 4-5. doi: 10.23736/S0375-9393.16.11654-2

13. Vasanth Karthik R, Ranganathan P, Kulkarni AP, Sharma KS. Does cuff pressure monitoring reduce postoperative pharyngolaryngeal adverse events after LMA-ProSeal insertion? A parallel group randomised trial. J Anesth 2014; 28: 662-667. doi: $10.1007 / \mathrm{s} 00540-014-1811-0$

14. Vannucci A, Rossi IT, Prifti K, Kallogjeri D, Rangrass G, DeCresce D, et al. Modifiable and nonmodifiable factors associated with perioperative failure of extraglottic airway devices. Anesth analg 2017 Dec 15. doi: 10.1213/ANE.0000000000002659. [epub ahead of print]

15. Brimacombe J, Holyoake L, Keller C, Brimacombe N, Scully M, Barry J, et al. Pharyngolaryngeal, neck, and jaw discomfort after anesthesia with the face mask and laryngeal mask airway at high and low cuff volumes in males and females. Anesthesiology 2000; 93: 26-31

16. Van Zundert AAJ, Gatt SP, Kumar CM, Van Zundert TCRV, Pandit JJ. 'Failed supraglottic airway': an algorithm for suboptimally placed supraglottic airway devices based on videolaryngoscopy. Br J Anaesth 2017; 118: 645-649. doi: 10.1093/bja/aex093

17. Esteller-Moré E, Ibañez J, Matiño E, Ademà JM, Nolla M, Quer IM. Prognostic factors in laryngotracheal injury following intubation and/or tracheotomy in ICU patients. Eur Arch Otorhinolaryngol 2005; 262: 880-883. doi: 10.1007/s00405005-0929-y

18. Tan KL, Chong AW, Amin MA, Raman R. Iatrogenic tracheal flap mimicking tracheal stenosis with resultant stridor. J Laryngol Otol 2012; 126: 751-755. doi: 10.1017/S0022215112000795

19. Goldmann K, Kuhlmann S, Gerlach M, Bornträger C. Removal of the laryngeal mask airway in the post-anesthesia care unit. A means of process optimization?. Anaesthesist 2011; 60: 10021008. doi: 10.1007/s00101-011-1936-6
20. Ashay NA, Wasim S, Anil TB. Propofol requirement for insertion of I-gel versus laryngeal mask airway: A comparative dose finding study using Dixon's up-and-down method. J Anaesthesiol Clin Pharmacol 2015; 31: 324-328. doi: 10.4103/0970-9185. 161666

21. Mourão J, Neto J, Luís C, Moreno C, Barbosa J, Carvalho J, et al. Dental injury after conventional direct laryngoscopy: a prospective observational study. Anaesthesia 2013; 68: 10591065. doi: 10.1111/anae.12342

22. Carassiti M, Zanzonico R, Cecchini S, Silvestri S, Cataldo R, Agrò FE. Force and pressure distribution using Macintosh and GlideScope laryngoscopes in normal and difficult airways: a manikin study. Br J Anaesth 2012; 108: 146-151. doi: 10.1093/ bja/aer304

23. Nicholson A, Cook TM, Smith AF, Lewis SR, Reed SS. Supraglottic airway devices versus tracheal intubation for airway management during general anaesthesia in obese patients. Cochrane Database Syst Rev 2013 Sep 9; (9): CD010105. doi: 10.1002/14651858. CD010105.pub2

24. Perelló-Cerdŕ L, Fàbregas N, López AM, Rios J, Tercero J, Carrero E, et al. ProSeal Laryngeal Mask Airway Attenuates Systemic and Cerebral Hemodynamic Response During Awakening of Neurosurgical Patients: A Randomized Clinical Trial. J Neurosurg Anesthesiol 2015; 27: 194-202. doi: 10.1097/ ANA.0000000000000108

25. Galgon RE, Schroeder K, Joffe AM. The self-pressurising air$\mathrm{Q}{ }^{\circledR}$ Intubating Laryngeal Airway for airway maintenance during anaesthesia in adults: a report of the first 100 uses. Anaesth Intensive Care 2012; 40: 1023-1027

26. Park SK, Choi GJ, Choi YS, Ahn EJ, Kang H. Comparison of the i-gel and the laryngeal mask airway proseal during general anesthesia: a systematic review and meta-analysis. PLoS One 2015; 26; 10: e0119469. doi: 10.1371/journal.pone.0119469

27. Wong DT, Tam AD, Mehta V, Raveendran R, Riad W, Chung FF. New supraglottic airway with built-in pressure indicator decreases postoperative pharyngolaryngeal symptoms: a randomized controlled trial. Can J Anaesth 2013; 60: 1197-1203. doi: 10.1007/s12630-013-0044-2

28. Hensel M, Güldenpfennig T, Schmidt A, Krumm M, Kerner T, Kox WJ. Digital palpation of the pilot balloon vs. continuous manometry for controlling the intracuff pressure in laryngeal mask airways. Anaesthesia 2016; 71: 1169-1176. doi: 10.1111/ anae. 13566

29. Sorbello M, Zdravkovic I. Time to monitor cuff pressures and to start "thinking supraglottic". Minerva anestesiol 2018;84: 124-125. doi: 10.23736/S0375-9393.17.12094-8

30. Sorbello M, Micaglio M, Zdravkovic I, Gaçonnet C, Skinner M. Pressure, volume and temperature: Boyle's law rules airways. Minerva Anestesiol 2018 Apr 5. doi: 10.23736/S03759393.18.12684-8. [Epub ahead of print]

31. Pavoni V, Gianesello L, DI Giacinto I, Sorbello M. The search for perfect supraglottic airway device: but I still haven't found what I am looking for. Minerva Anestesiol 2018; 84: 411-413. doi: $10.23736 / \mathrm{S} 0375-9393.17 .12083-3$

Rom J Anaesth Intensive Care 2018; 25: 7-9 